\title{
Study on Properties of Poly(vinyl alcohol)/Polyacrylonitrile Blend Film
}

\author{
Guoquan Zhu, Fagang Wang, Kejing Xu, Qiaochun Gao, Yuying Liu \\ School of Materials Science and Engineering, Shandong University of Technology
}

\begin{abstract}
In this work, a series of poly(vinyl alcohol) (PVA)/polyacrylonitrile (PAN) blend films with different PAN mole contents were prepared by casting the polymer blend solution in dimethylsulfoxide (DMSO). Surface morphologies of PVA/PAN blend films were analyzed by Scanning Electronic Microscopy (SEM) and Atomic Force Microscopy (AFM). Thermal, mechanical, and chemical properties of PVA/PAN blend films were investigated by Differential Scanning Calorimetry (DSC), Thermogravimetric Analysis (TGA), Tensile Tests, and Surface Contact Angle Tests. The results showed that the introduction of PAN could exert marked effects on the properties of PVA films.
\end{abstract}

Keywords: Properties, PVA/PAN blend, film, morphology.

\section{Introduction}

Based on its easy preparation, nontoxic, noncarcinogenic, biodegradable and bioadhesive characteristics, excellent chemical resistance and physical properties, poly(vinyl alcohol) (PVA) a water-soluble polyhydroxy polymer has received much attention for its potential applications ${ }^{[1-4]}$. PVA as excellent biomaterials is capable of simulating natural tissues, contact lenses, the lining for artificial organs, and drug delivery, etc ${ }^{[5-8]}$. Although PVA holds good mechanical properties in the dry state, its high hydrophilicity limits its applications ${ }^{[9]}$. Relative to homopolymer, some of the polymer blends usually exhibit unexpected properties ${ }^{[1]}$.

Nowadays, polymer blending has been a most useful method for improving or modifying the physicochemical properties of polymer materials ${ }^{[1]}$. An important property for the polymer blend is the miscibility of its ingredients, as it affects the mechanical properties, the morphology, the permeability, and the degradation ${ }^{[1,10]}$. Numerous investigations regarding the miscibility in multicomponent polymer systems have been reported. Among them, the polymer blends between biopolymers and synthetic polymers are of particular significance as they could be used as biomedical and biodegradable materials ${ }^{[1-13]}$. In order to open up the possibilities for the applied fields, the miscibility of each component polymer is also interesting and importance. One of the driving forces for thermodynamic miscibility is, interchain hydrogen bonds or van der Waals forces. Recently, because environmental issues for nonbiodegradable polymers such as cellulose and its derivatives, PVA, and polyesters have started to attract attention and interest with a view to altering their inherent properties by various methods. Therefore, cellulosics or PVA are once again being considered as possible candidates for industrial use ${ }^{[12]}$.

As known, polyacrylonitrile (PAN) presents good mechanical property and good hydrophobicity and has been widely used as film materials ${ }^{[14-19]}$. The introduction of PAN into PVA film is expected to adjust the physicochemical properties of PVA film. The formation of hydrogen bonds between PVA chains and PAN segments could promote the miscibility of PVA and PAN. However, to the best of our knowledge, no experimental work has been reported on the properties of PVA/PAN blend film so far. In the present work, a series of PVA/PAN blend films with different PAN mole contents were prepared by casting the polymer blend solution in DMSO. Surface morphologies of PVA/PAN blend films were analyzed by SEM and AFM techniques. Thermal, mechanical, and chemical properties of PVA/PAN blend films were investigated by DSC, TGA, Tensile Tests, and Surface Contact Angle Tests. The results revealed that the introduction of PAN could exert great effects on the properties of PVA films.

\section{Experimental}

\section{Materials}

Poly(vinyl alcohol $) \quad\left(M_{\mathrm{w}}=90000\right.$, degree of hydrolysis $99 \mathrm{~mol} \%$ ) was purchased from Sigma, Inc., and used without further purification. Polyacrylonitrile $\left(M_{\mathrm{w}}=30000\right)$ was purchased from Qilu Petrochemical Fiber Plant (China). Dimethylsulfoxide (DMSO) was of analytical grade and used without further purification.

\section{Preparation of PVA/PAN blend film}

PVA/PAN blend films were prepared by casting films from a $30 \%$ polymer blend solution in dimethylsulfoxide onto clean glass plates and drying them under vacuum at $55^{\circ} \mathrm{C}$. Also, it is found that, when PAN mole content in polymer blend is over $15 \%$, the polymer blend can not form continuous film. Figure 1 presents the proposed structure of PVA/PAN blend film showing the $\mathrm{H}$-bonding interaction between PVA and PAN.

\section{Scanning Electron Microscope (SEM)}

Morphologies of PVA/PAN blend films were observed using a scanning electron microscope (Sirin 200, FEI, Holland). Gold was sputtered on the samples in vacuum. Acceleration voltage was $10 \mathrm{kV}$.

\section{Atomic Force Microscopy (AFM)}

The surface morphologies of polymer blend films were characterized on a NanoScope IIIA MultiMode AFM instrument (Digital Instruments Inc., USA) in air at ambient conditions using tapping mode probes with constant amplitude $(200 \mathrm{mV})$. The rotated tapping mode etched silicone probe with a resonance frequency of $250 \mathrm{kHz}$ was used. The height images were recorded at the resonance frequency of the cantilever with a scan rate of $1 \mathrm{~Hz}^{[20]}$. 


\section{Differential Scanning Calorimetry (DSC)}

DSC measurements were made on a DSC Q100 (TA, USA) differential scanning calorimeter, the temperature was calibrated with indium in a nitrogen atmosphere. About $8 \mathrm{mg}$ samples were weighed very accurately. The temperature was controlled in the range of $30-250{ }^{\circ} \mathrm{C}$, the heating rate was $10{ }^{\circ} \mathrm{C} / \mathrm{min}$.

\section{Thermogravimetric Analysis (TGA)}

Thermogravimetric analysis (TGA) was carried out on a NETZSCH STA 4490 C TG-DTA analyzer (Germany) at a heating rate of $10^{\circ} \mathrm{C} / \mathrm{min}$ under nitrogen atmosphere over the temperature range of $30-650{ }^{\circ} \mathrm{C}$. Samples of approximately $13 \mathrm{mg}$ were used for the TGA measurements.

\section{Tensile tests}

Tensile tests were carried out with an Instron 4468 machine (USA). The crosshead speed was set to $50 \mathrm{~mm} / \mathrm{min}$. For each data point, five samples were tested and the average value was taken.

\section{Surface contact angle tests}

The static contact angle was measured with an optical contact angle meter CAM 200 (KSV Instrument Ltd., Finland). A $5 \mu \mathrm{L}$ drop of pure distilled water was placed on the polymer blend film surface using a syringe with a 22-gauge needle. The measurements of each contact angle were performed within $10 \mathrm{~s}$ after each drop to ensure that the droplet did not soak into the compact. The surface contact angles were the mean of five determinations ${ }^{[20]}$.

\section{Results and Discussion}

\section{SEM analysis}

Figure 2 shows the surface micrographs of PVA/PAN blend films with various PAN mole contents: (a) 0 , (b) $2 \%$, (c) $5 \%$, (d) $8 \%$, and (e) $10 \%$. As it can be seen from Figure 2, the introduction of PAN into PVA changed the surface morphology of the PVA film. With the increase of the PAN mole contents, the surface morphologies of PVA/PAN blend films became uneven and the phase-separation phenomenon occurred. As mentioned above, PVA segments and PAN segments could exert interaction by entanglement ${ }^{[1]}$ and by forming intermolecular hydrogen bonds ${ }^{[21]}$, indicating the introduction of PAN into PVA changed the microstructure of PVA film. This phenomenon reveals that the change of the morphologies of PVA film surface could be attributed to the introduction of PAN segments.

\section{AFM analysis}

As noted, the AFM height images presented the surface roughness of polymer film ${ }^{[22-24]}$. Figure 3 presents the AFM 3D height mode images of PVA/PAN blend film surface with different PAN mole contents: (a) 0 , (b) $2 \%$, (c) $5 \%$, (d) $8 \%$, and (e) $10 \%$. As seen from Figure 3, the surface colors of the PVA/PAN blend films are different. The area ratios of the brighter domains (corresponding to higher part) to the darker domains (corresponding to lower part) are also various, suggesting that the surface roughness of the polymre blend film is changing with the increase of PAN mole contents in the polymer blend ${ }^{[23,24]}$. This phenomenon indicates that the surface roughness difference of polymer blend film could also be attributed to the introduction of PAN segments.

\section{DSC analysis}

Figure 4 indicates the DSC curves of PVA/PAN blend film with various PAN mole contents: (a) 0 , (b) $2 \%$, (c) $5 \%$, (d) $8 \%$, and (e) $10 \%$. As is shown in Figure 4, the melting temperature of PVA segments in PVA/PAN blend film decreased with the increase of PAN content in polymer blend film. As known, PAN segments and PVA chains could exert interaction ${ }^{[1,21]}$ and the interaction partially destroyed the crystallinity of the PVA segments, suggesting the decrease of the melting temperature of PVA segments in polymer blend film was connected with the introduction of PAN segments.

\section{TGA analysis}

Figure 5 exhibits the DTG curves of PVA/PAN blend film with different PAN mole contents: (a) 0, (b) 2\%, (c) 5\%, (d) $8 \%$, and (e) $10 \%$, the corresponding data are listed in Table 1. As shown in Figure 5 and Table 1, the maximum degradation temperature of the polymer blend film decreases with the increase of PAN mole contents in polymer blend film. As discussed above, PAN segments and PVA chains could exert interaction ${ }^{[1,21]}$ and the interaction partially destroyed the crystallinity of the PVA chains, indicating that the decrease of the maximum degradation temperature of PVA segments in the polymer blend film was also related with the introduction of PAN segments.

\section{Tensile analysis}

Figure 6 shows the relationship between the tensile strength of PVA/PAN blend film and PAN mole contents. As seen from Figure 6, the tensile strength of the polymer blend film increased with the increase of PAN mole contents in the polymer blend film. Compared with PVA segments, PAN segments hold better mechanical property ${ }^{[19]}$, and the introduction of PAN segments into PVA film could promote the tensile strength of the polymer blend film. This phenomenon proves that the increase of the tensile strength of the polymer blend film was concerned with the introduction of PAN segments.

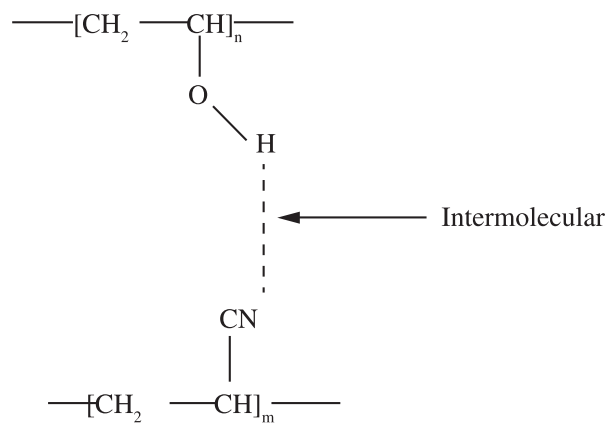

Figure 1. Proposed structure of PVA/PAN blend film showing the H-bonding interaction between PVA and PAN.

Table 1. Maximum degradation temperature of PVA/PAN blend film with different PAN mole contents.

\begin{tabular}{cc}
\hline PAN content $(\mathbf{m o l} \%)$ & $\begin{array}{c}\text { Maximum degradation } \\
\text { temperature }\left({ }^{\circ} \mathbf{C}\right)\end{array}$ \\
\hline 0 & 266.3 \\
2 & 261.2 \\
5 & 257.4 \\
8 & 250.6 \\
10 & 248.8 \\
\hline
\end{tabular}




\section{Surface contact angle tests analysis}

Figure 7 presents the relationship between the surface contact angle of PVA/PAN blend film and PAN mole contents. As is shown in Figure 7, the surface contact angle of the polymer blend film increased with the increase of PAN mole contents in the polymer blend film, suggesting that the hydrophilicity of the polymer blend film decreased. As known, PAN segments hold better hydrophobicity ${ }^{[14]}$ and the introduction of PAN segments into PVA film could decrease the hydrophilicity of the polymer blend film. This situation demonstrates that the increase of the surface contact

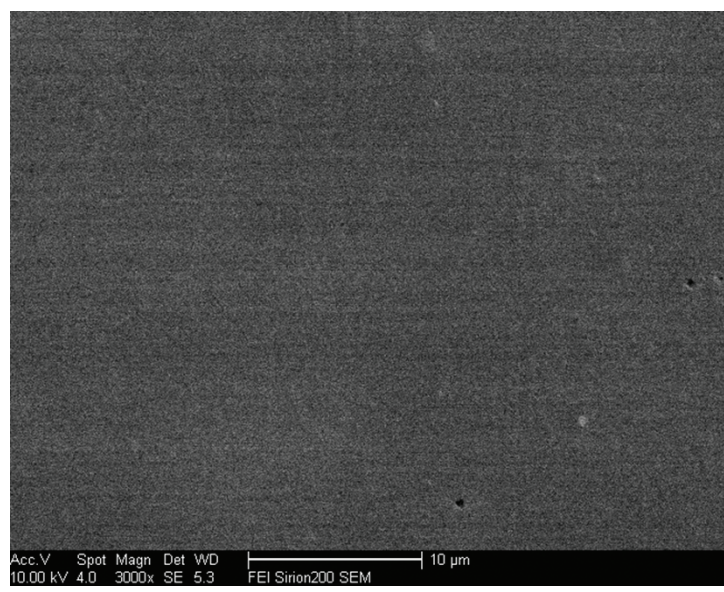

(a)

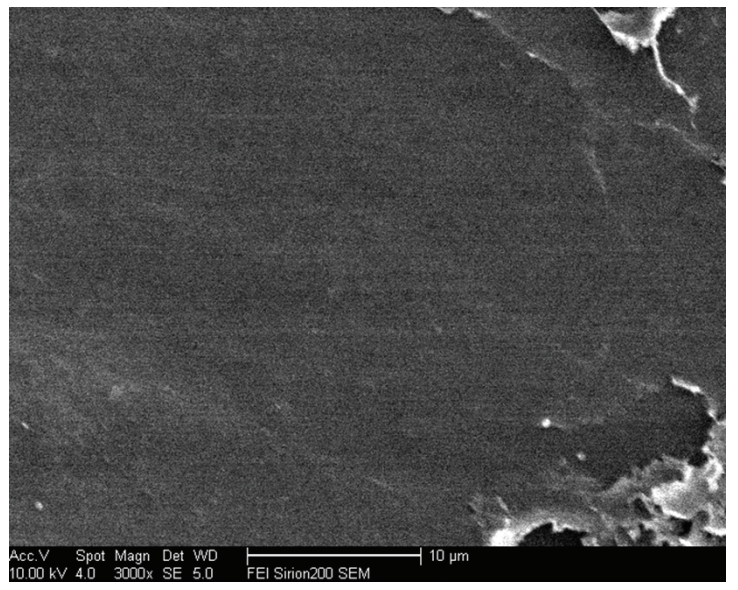

(c) angle of the polymer blend film was related to the introduction of the hydrophobic PAN segments.

\section{Conclusion}

A series of PVA/PAN blend films with various PAN mole contents were prepared by casting the polymer blend solution in DMSO. SEM, AFM, DSC, TGA, tensile tests, and surface contact angle tests techniques were used to investigate the surface morphology and the properties of PVA/PAN blend film. SEM

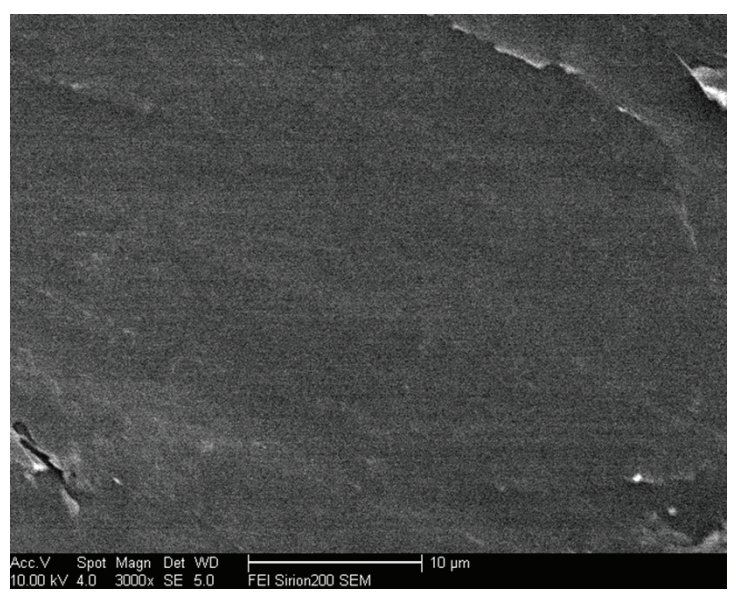

(b)

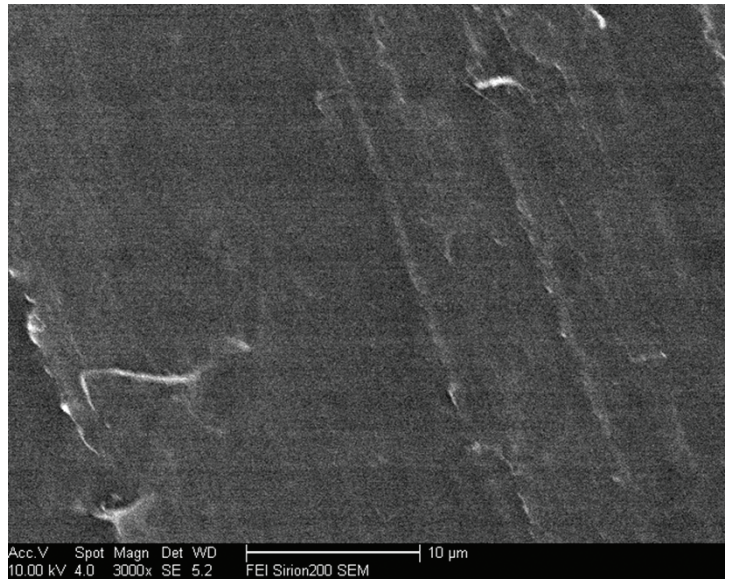

(d)

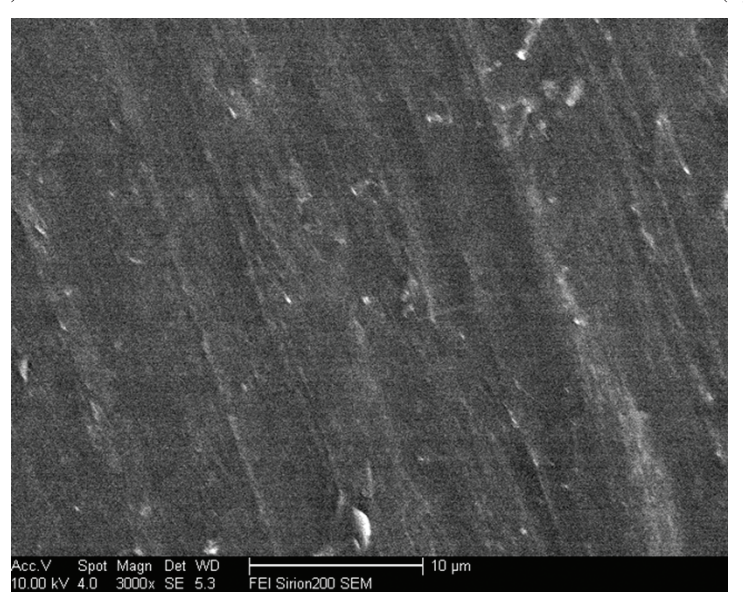

(e)

Figure 2. SEM micrographs of PVA/PAN blend film surface with different PAN mole contents: (a) 0 , (b) $2 \%$, (c) $5 \%$, (d) $8 \%$, and (e) $10 \%$. (magnification $3000 \times$ ). 
micrographs indicated that the introduction of PAN segments changed the surface morphologies of PVA films. AFM images proved that the introduction of PAN chains changed the surface

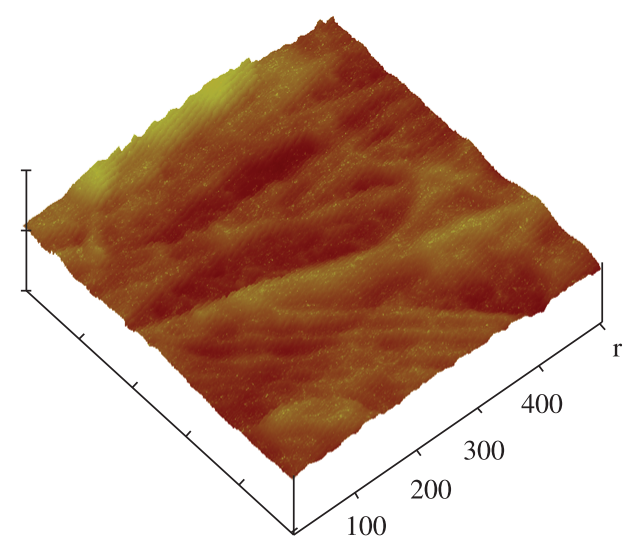

(a)

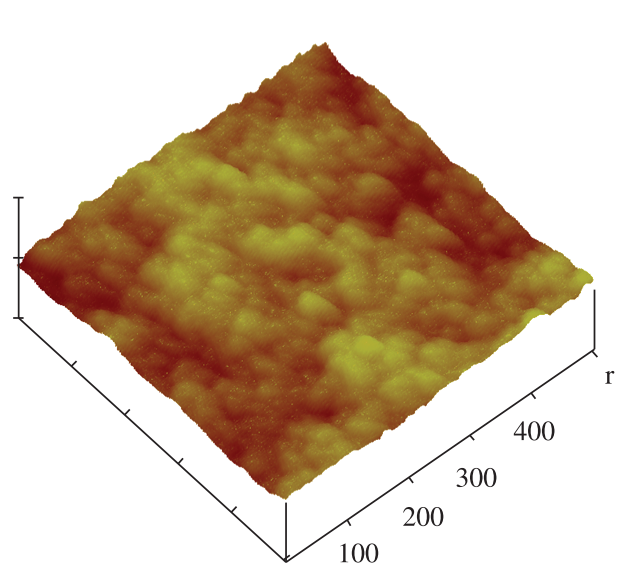

roughness of PVA films. DSC measurements demonstrated that the introduction of PAN chains decreased the melting temperature of PVA segments in the polymer blend films. TGA tests indicated that

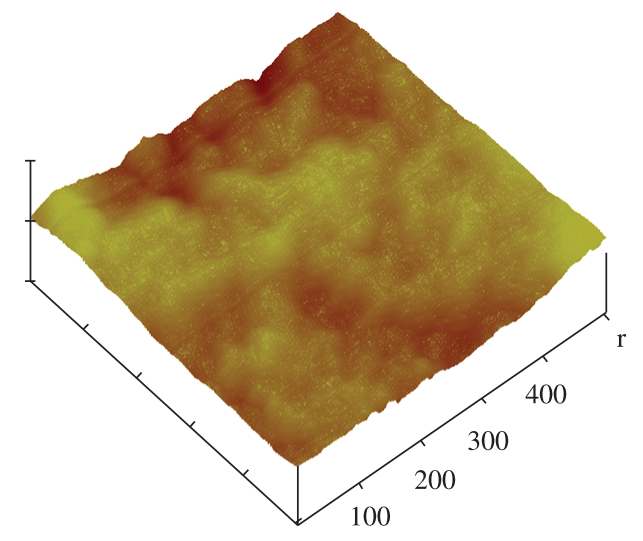

(b)

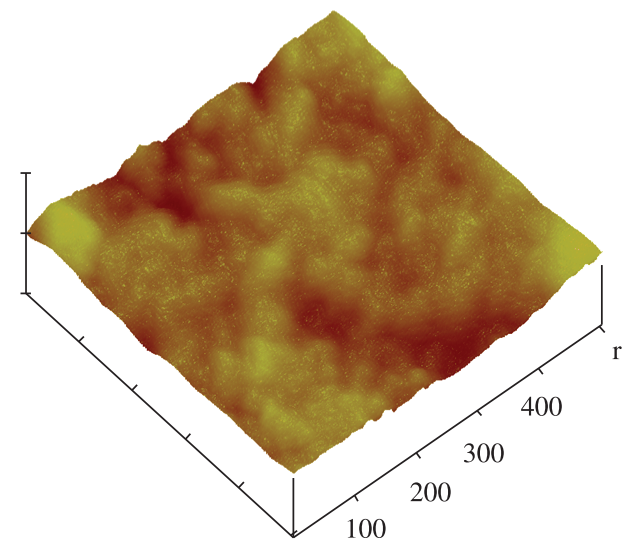

(d)

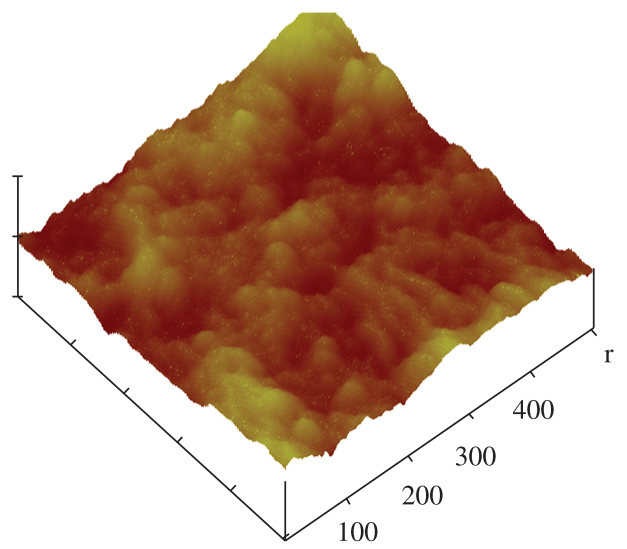

(e)

Figure 3. AFM 3D height mode images of PVA/PAN blend film surface with various PAN mole contents: (a) 0, (b) $2 \%$, (c) $5 \%$, (d) $8 \%$, and (e) $10 \%$. Each image is $500 \mathrm{~nm}$ by $500 \mathrm{~nm}$. 


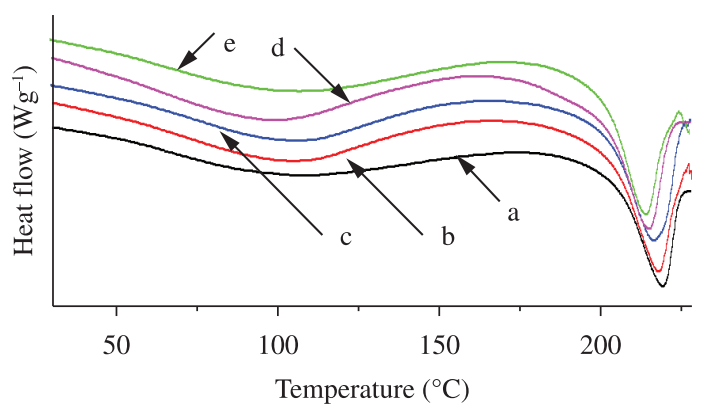

Figure 4. DSC curves of PVA/PAN blend film with various PAN mole contents: (a) 0 , (b) $2 \%$, (c) $5 \%$, (d) $8 \%$, and (e) $10 \%$.

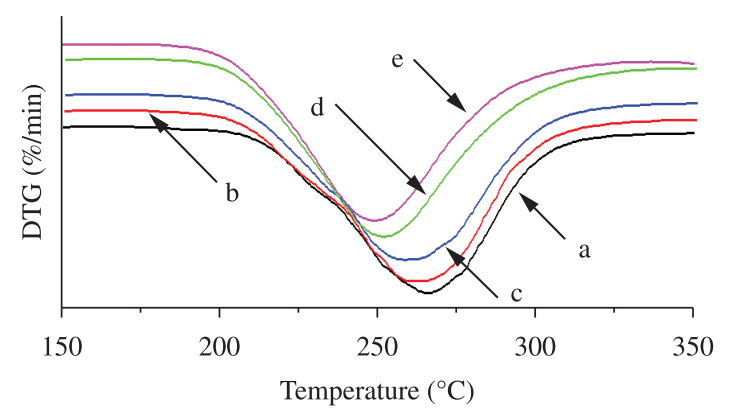

Figure 5. DTG curves of PVA/PAN blend film with different PAN mole contents: (a) 0 , (b) $2 \%$, (c) $5 \%$, (d) $8 \%$, and (e) $10 \%$.

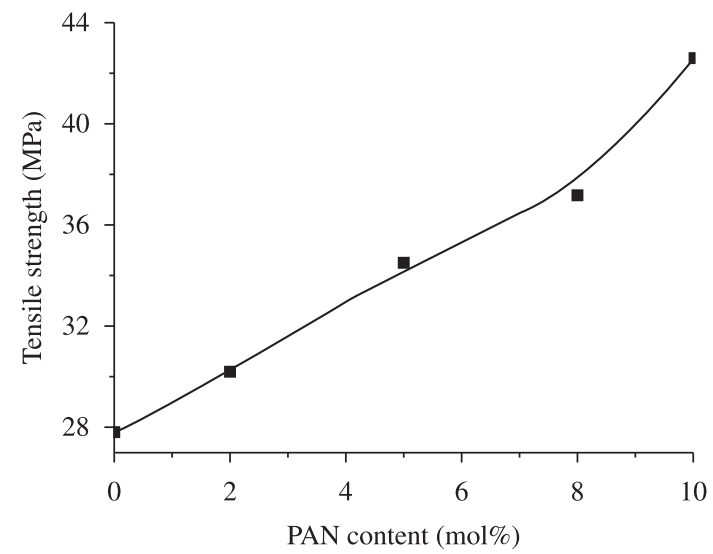

Figure 6. Relationship between the tensile strength of PVA/PAN blend film and PAN mole contents.

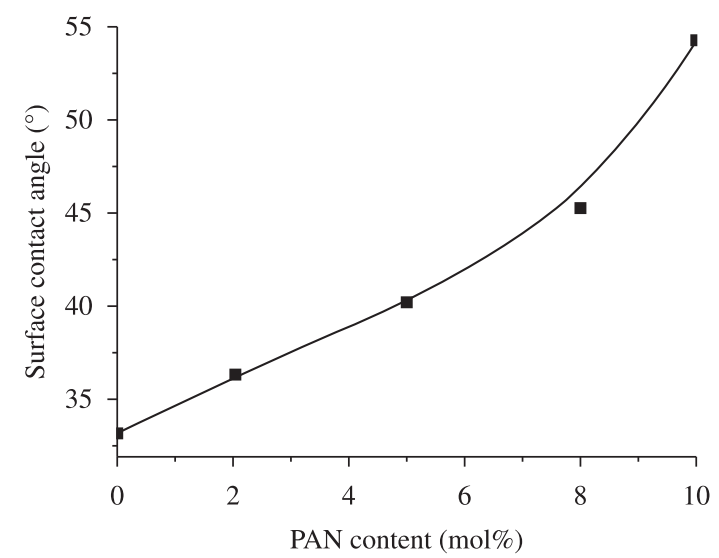

Figure 7. Relationship between the surface contact angle of PVA/PAN blend film and PAN mole contents. the introduction of PAN chains decreased the maximum degradation temperature of the polymer blend films. Tensile tests verified that the tensile strength of the polymer blend films increased with the increase of PAN mole contents. Surface contact angle tests attested that the introduction of PAN segments increased the hydrophobicity of the polymer blend films.

\section{Acknowledgements}

This work is supported by the Natural Science Foundation of Shandong Province (No. ZR2011EMM009).

\section{References}

1. Park, J. S.; Park, J. W. \& Ruckenstein, E. - Polymer, 42, p.4271 (2001). http://dx.doi.org/10.1016/S0032-3861(00)00768-0

2. Papancea, A.; Valente, A. J. M.; Patachia, S.; Miguel, M. G. \& Lindman, B. - Langmuir, 24, p.273 (2008). PMid:18052399. http:// dx.doi.org/10.1021/la702639d

3. Hassan, C. M. \& Peppas, N. A. - Adv. Polym. Sci., 153, p.37 (2000). http://dx.doi.org/10.1007/3-540-46414-X_2

4. DeMerlis, C. C. \& Schoneker, D. R. - Food Chem. Toxicol., 41, p.319 (2003). http://dx.doi.org/10.1016/S0278-6915(02)00258-2

5. Chua, C. K.; Leong, K. F.; Tan, K. H.; Wiria, F. E. \& Cheah, C. M. - J. Mater. Sci. -Mater. M., 15, p.1113 (2004). PMid:15516872. http:// dx.doi.org/10.1023/B:JMSM.0000046393.81449.a5

6. Hyon, S. H.; Cha, W. I.; Ikada, Y.; Kita, M.; Ogura, Y. \& Honda, Y. - J. Biomater. Sci. -Polym. E., 5, p.397 (1994).

7. Dai, W. S. \& Barbari, T. A. - Biomaterials, 21, p.1363 (2000). http:// dx.doi.org/10.1016/S0142-9612(00)00022-3

8. Coluccio, M. L.; Ciardelli, G.; Bertoni, F.; Silvestri, D.; Cristallini, C.; Giusti, P. \& Barbani, N. Macromol. Biosci., 6, p.403 (2006). PMid:16775815. http://dx.doi.org/10.1002/mabi.200600022

9. Hodge, R. M.; Edward, G. H. \& Simon, G. P. - Polymer, 37, p.1371 (1996). http://dx.doi.org/10.1016/0032-3861(96)81134-7

10. Nishio, Y. \& Manley, R. - Macromolecules, 21, p.1270 (1988). http:// dx.doi.org/10.1021/ma00183a016

11. Kondo, T.; Sawatari, C.; Manley, R. \& Gray, D. G. - Macromolecules, 27, p.210 (1994). http://dx.doi.org/10.1021/ma00079a031

12. Sawatari, C. \& Kondo, T. - Macromolecules, 32, p.1949 (1999). http:// dx.doi.org/10.1021/ma980900o

13. Lio, K.; Minoura, N. \& Nagura, M. - Polymer, 36, p.2579 (1995). http://dx.doi.org/10.1016/0032-3861(95)91204-K

14. Wan, L. S.; Xu, Z. K.; Huang, X. J.; Che, A. F. \& Wang, Z. G. - J. Membrane Sci., 277, p.157 (2006). http://dx.doi.org/10.1016/j. memsci.2005.10.037

15. Ulbricht, M. \& Belfort, G. - J. Membrane Sci., 111, p.193 (1996). http://dx.doi.org/10.1016/0376-7388(95)00207-3

16. Jung, B. - J. Membrane Sci., 229, p.129 (2004). http://dx.doi. org/10.1016/j.memsci.2003.10.020

17. Frahn, J.; Malsch, G.; Matuschewski, H.; Schedler, U. \& Schwarz, H. H. - J. Membrane Sci., 234, p.55 (2004). http://dx.doi.org/10.1016/j. memsci.2003.12.017

18. Hicke, H. G.; Lehmann, I.; Malsh, G.; Ulbricht, M. \& Becker, M. - J. Membrane Sci., 198, p.187 (2002). http://dx.doi.org/10.1016/S03767388(01)00595-6

19. You, H.; Yang, Y.; Li, X.; Zhang, K.; Wang, X. F.; Zhu, M. F. \& Hsiao, B. S. - J. Membrane Sci., 394-395, p.241 (2012). http://dx.doi. org/10.1016/j.memsci.2011.12.047

20. Bai, L. Q.; Zhu, L. J.; Min, S. J.; Liu, L.; Cai, Y. R. \& Yao, J. M. - Appl. Surf. Sci., 254, p.2988 (2008). http://dx.doi.org/10.1016/j.apsusc.2007.10.049 
21. Jin, L. \& Bai, R. B. - Langmuir, 18, p.9765 (2002). http://dx.doi. org/10.1021/la0259171

22. Yamamoto, S.; Tsujii, Y. \& Fukuda, T. - Polymer, 42, p.2007 (2001). http://dx.doi.org/10.1016/S0032-3861(00)00525-5

23. Lee, M. Y.; Kim, S. H.; Ganapathy, H. S.; Kim, S. W. \& Lim, K. T. - Ultramicroscopy, 108, p.1210 (2008). PMid:18547731. http:// dx.doi.org/10.1016/j.ultramic.2008.04.017
24. Fasolka, M. J.; Mayes, A. M. \& Magonov, S. N. - Ultramicroscopy, 90, p.21 (2001). http://dx.doi.org/10.1016/S0304-3991(01)00129-2

Received: 08/02/12

Revised: 26/07/12

Accepted: 06/08/12 